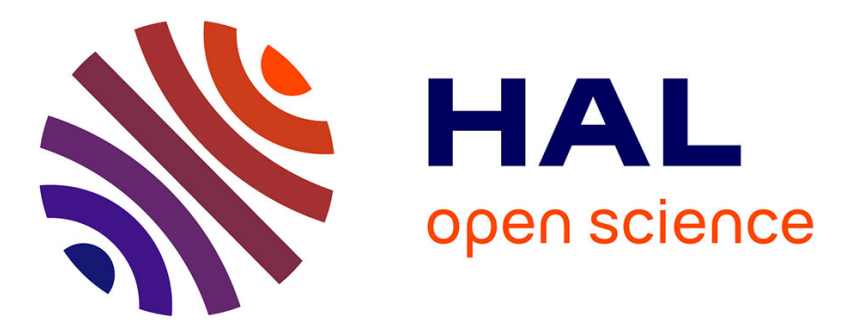

\title{
Characterization of particulate matter emissions in urban train braking - An investigation of braking conditions influence on a reduced-scale device
}

Charlène Octau, Damien Méresse, Michel Watremez, Jesse Schiffler, Marc Lippert, Laurent Keirsbulck, Laurent Dubar

\section{To cite this version:}

Charlène Octau, Damien Méresse, Michel Watremez, Jesse Schiffler, Marc Lippert, et al.. Characterization of particulate matter emissions in urban train braking - An investigation of braking conditions influence on a reduced-scale device. Environmental Science and Pollution Research, 2020, 27 (15), pp.18615-18631. 10.1007/s11356-020-08337-8 . hal-03440107

\section{HAL Id: hal-03440107 \\ https: / uphf.hal.science/hal-03440107}

Submitted on 22 Nov 2021

HAL is a multi-disciplinary open access archive for the deposit and dissemination of scientific research documents, whether they are published or not. The documents may come from teaching and research institutions in France or abroad, or from public or private research centers.
L'archive ouverte pluridisciplinaire HAL, est destinée au dépôt et à la diffusion de documents scientifiques de niveau recherche, publiés ou non, émanant des établissements d'enseignement et de recherche français ou étrangers, des laboratoires publics ou privés. 
Noname manuscript No.

(will be inserted by the editor)

\title{
Characterization of particulate matter emissions in
}

urban train braking - An investigation of braking

conditions influence on a reduced-scale device

Charlene OCTAU • Damien MERESSE

* . Michel WATREMEZ • Jesse

SCHIFFLER · Marc LIPPERT · Laurent

KEIRSBULCK · Laurent DUBAR

Received: date / Accepted: date

\begin{abstract}
The particulate matter emissions related to the braking of railway rolling stock are investigated using a reduced scale braking device. Samples of organic materials and cast iron discs are tested for different nominal contact pressures and disc surface temperatures, representative of real conditions. The aim of this work is to investigate the influence of braking conditions on the global amount of particles emitted, their distribution in number and size, and their morphological and chemical characteristics. To be representative, the tested conditions are Damien MERESSE

* Corresponding Author

LAMIH Laboratory, UMR CNRS 8201, University of Hauts-de-France, 59300 Valenciennes, France

Tel.: +33 327511986

E-mail: dmeresse@uphf.fr
\end{abstract}


designed to dissipate the same amount of energy for all the braking events by adjusting the pad application duration. The results show that for the same dissipated energy, a temperature increase above a transition value in the range of $230-280^{\circ} \mathrm{C}$ depending on the braking conditions, modifies the size and number distributions of the generated particles. The results obtained are of interest to better represent their propagation through CFD modelling according to the characteristic of the particle emission.

Keywords Railway · Disc Braking · Non Asbestos Organic Pads · Non-Exhaust Emissions · Airborne Particles · Air Quality

\section{Introduction}

Braking has been identified as the second source of $\mathrm{PM}_{10}$ emissions (i.e. airborne particle with an aerodynamic diameter of less than $10 \mu \mathrm{m})$ in urban road traffic. Moreover, this is the primary source in underground railway traffic (Grigoratos and Martini, 2015),(Thorpe and Harrison, 2008). It is mainly in urban areas that these particles are emitted in large quantities, due to the concentration of human activities and the associated road traffic for people transportation (Querol et al., 2004). About $35 \%$ of brake pad mass loss is released into the air and $50 \%$ of the wear debris generated become airborne (Garg et al., 2000; Sanders et al., 2003). Moreover, Particulate Matter (PM) induces adverse health effects and environmental changes (Grantz et al., 2003; Hansen et al., 2016). As an example, it has been shown that PM are associated to cardiovascular (Franck et al., 2011; Wu et al., 2012), respiratory (Martins et al., 2015; Clifford et al., 2018) and neuronal (Solaimani et al., 2017) diseases, causing up to 48,000 premature 
deaths in France (Pascal et al., 2016). Several studies have been conducted on disc brake for decades, but they have mainly focused on emissions characterization in order to better understand their interaction with human beings and the environment. Some of those studies have been conducted on real scale (field tests) (Abbasi et al., 2012b; Wahlström et al., 2010c), on system scale (Sanders et al., 2003; Mosleh et al., 2004; Kukutschová et al., 2011; Namgung et al., 2016) and on model scale (Wahlström et al., 2010c,b; Abbasi et al., 2012a; Alemani et al., 2018), providing a qualitative description and correlations on particle emission in terms of size distribution, morphology and chemical composition. However, there is a lack of information on how the braking conditions influence the PM generation. Nevertheless some interesting observations are provided by those studies. (Garg et al., 2000) performed a brake dynamometer study on particles emissions from car brakes with non-asbestos organic pads (NAO) and semi-metallic pads (SM). The authors noticed a mass reduction and an increase in particle number for contact temperature close to $400^{\circ} \mathrm{C}$ during their investigations. (Kukutschová et al., 2011) also carried out car brake dynamometer study with low-metallic pads (LM) and noticed an increase in particle number concentration in the ultra-fine particle fraction $(<100 \mathrm{~nm})$ when the temperature exceeded $300^{\circ} \mathrm{C}$ (Kukutschová et al., 2011). Similarly, (Wahlström et al., 2010c,a,d,b) conducted studies on LM and NAO car brake materials against cast iron, using a pin-on-disc machine, a disc brake assembly test stand and field measurements. They found that the ultra-fine number concentration increases for high load tests. Therefore, (Alemani et al., 2018) tried to point out the influence of braking conditions and also highlighted that the system temperature significantly affects the ultra-fine fraction levels during their investigations using a pin-on-disc tribometer on car brake materials. 
Extensive review of relevant literature can be found in (Grigoratos and Martini, 2015), (Abbasi and Sellgren, 2013). It appears from the above-mentioned studies that the airborne brake particles have been investigated for different materials and braking conditions. Nevertheless, the studies were carried out with several parameters varying at the same time hindering the understanding of the actual influence of these parameters on emissions. Besides, the results provided in these studies refer to total quantities measured during a braking, braking sequence or experiment, and not to real-time measurements, although in some cases these are carried out (Alemani et al., 2018; Abbasi and Sellgren, 2013; Wahlström et al., 2010b; Nosko et al., 2015; Kukutschová et al., 2011)

The objective of this study is to provide additional information on the influence of braking conditions such as contact pressure and disc temperature, in particular regarding the range of particles emitted, their shape and composition. Knowledge of the nature of these particles (size, shape and composition) and their real-time emission is essential to develop fluid numerical models able of predicting correctly their propagation close the location of their production. There are to major aims for this work : give rules to choose the friction conditions which give the lower particle emission for a given dissipated kinetic energy and give rules for the particles injection properties in CFD model for study on their propagation in confined area, like subway station. The evaluation of the influence of these parameters on the nature of the emitted PM will be carried out on a pair of railway braking material, by varying one parameter at a time, while maintaining an equivalent dissipated energy. The characteristics of the emitted PM and the real-time distributions obtained will be presented. 


\section{Experimental methodology}

Two approaches are considered for the particle's characterization: a particle collection approach for off-line analysis and an instantaneous measurement approach with on-line measurement of the particle size distribution. The methodology applied in our study can be resumed by the Figure 1 . In the both approaches, the braking tests are performed on the High Speed Tribometer, an experimental platform of our laboratory which is designed for friction studies at high sliding speeds (Meresse et al., 2013; García et al., 2014).

\subsection{Experimental setup}

The HST consists of a high-speed machine tool used to get a disc rotation at a fixed position. The reduced disc is mounted vertically on the electro-spindle. The brake pads are mounted on a Kistler cell force to collect the normal and tangential forces. The cell can work up to $20 \mathrm{kN}$ in compression and $5 \mathrm{kN}$ in shear. It is fixed on a pneumatic guided cylinder as well as in most of suburban trains (Figure 2). A tachometer allows a measurement of the disc rotational speed at a frequency of $2 \mathrm{~Hz}$. The temperature is monitored using a digital laser pyrometer pointing at the edge of the friction track. The pyrometer can measure a temperature between 50 and $1200^{\circ} \mathrm{C}$ with an accuracy of $0.1^{\circ} \mathrm{C}$. The tests are computationally driven in speed and in load application, as suggested by (Abbasi and Sellgren, 2013), and the measured data are recorded simultaneously. The environment temperature and the relative humidity are measured during all the tests. They are respectively in the range of $20-25^{\circ} \mathrm{C}$ and $40-55 \%$ in the HST room. 


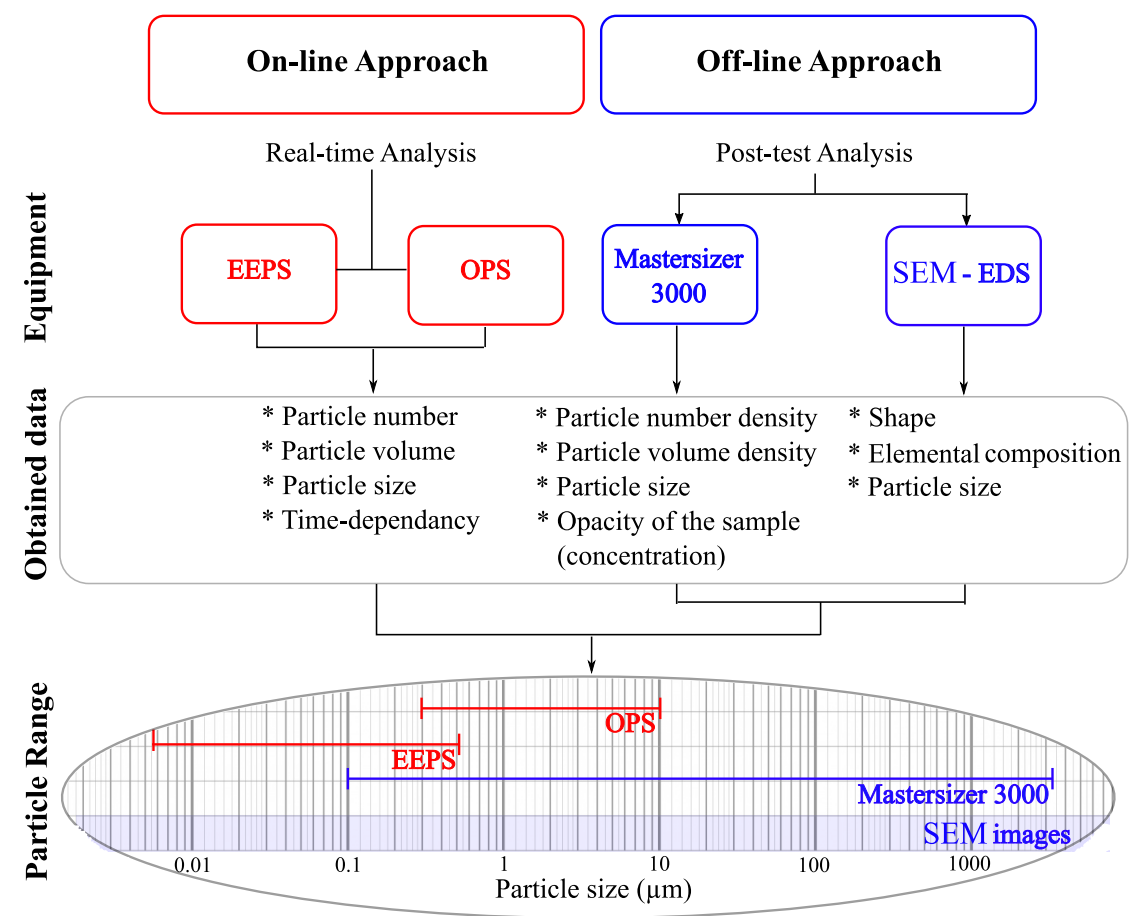

Fig. 1 Description of the experimental approach

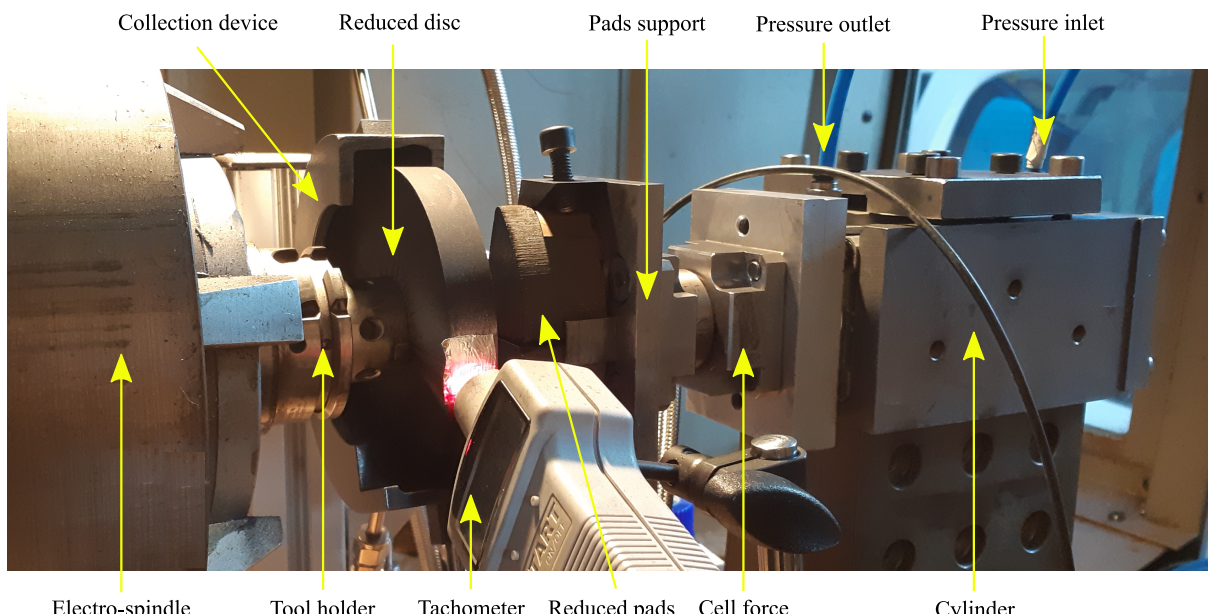

Fig. 2 Picture of the braking device and the collecting system. 
In order to ensure the collection of PM emitted during braking, a collection device (in the shape of a curved groove) is placed around the disc. In the case of the Off-line approach, the particles are placed in water to be analyzed later. Several braking events are performed in the same conditions to get a representative set of particles. As described on the figure 1, the post-test analysis can give information on the shape and the elemental composition. The morphology and elemental analysis of the collected particles were conducted using Field Emission Scanning Electron Microscopy (FE-SEM) coupled with Energy Dispersive Spectrometry (EDS). Then, information on the particle size and their density are obtained through a Mastersizer3000 device. This analyzer allows to measure particle size distributions from 0.1 to $3500 \mu \mathrm{m}$ in wet solutions. The pads are weighted using an analytical balance Kern AET $500-4$ (with precision of $0.1 \mathrm{mg}$ ), in order to evaluate the wear generated during the tests. Finally, the opacity of the solution gives also qualitative information about the particle concentration. In the case of the On-line approach, the particles are sampled through a probe, mounted on the collection device around the disc and distributed to an Optical Particle Sizer (OPS, TSI 3330) and an Engine Exhaust Particle Sizer (EEPS, TSI 3090). This combination is very similar to the assembly used by ((Namgung et al., 2016)). The EEPS sizes the particles according to their electrical mobility from $5.6 \mathrm{~nm}$ to 560 $\mathrm{nm}$ at $10 \mathrm{~Hz}$ with a 32 channels resolution. The OPS is able to size particles according to their optical properties and give an equivalent diameter in a range from $300 \mathrm{~nm}$ to $10 \mu \mathrm{m}$, at $1 \mathrm{~Hz}$ on 16 adjustable channels. 
2.2 Materials

The friction materials are obtained from a pair of unused brake materials from an urban train operating on the Parisian railway network. The disc is in grey cast iron with lamellar graphite and the pads are composed of an organic matrix with fillers and particles without asbestos. The lining contains a large portion of carbon compounds (resin and fillers) and iron in the form of oxides (abrasive fibers and powders). According to the supplier, it also contains majoritary the abrasive compounds given in Table 1, necessary for effective braking.

\begin{tabular}{|c|r|r|r|r|r|}
\hline Materials & Phenolic Resin & Ferrous oxydes & BaSO $_{4}$ & $\mathrm{MgO}$ & $\mathrm{Sb}_{2} \mathrm{~S}_{3}$ \\
\hline Density $\left(\mathrm{kg} / \mathrm{m}^{3}\right)$ & $\approx 1200$ & $5200-5800$ & 4500 & 3580 & 4640 \\
\hline
\end{tabular}

Table 1 Brake pads compounds - Density

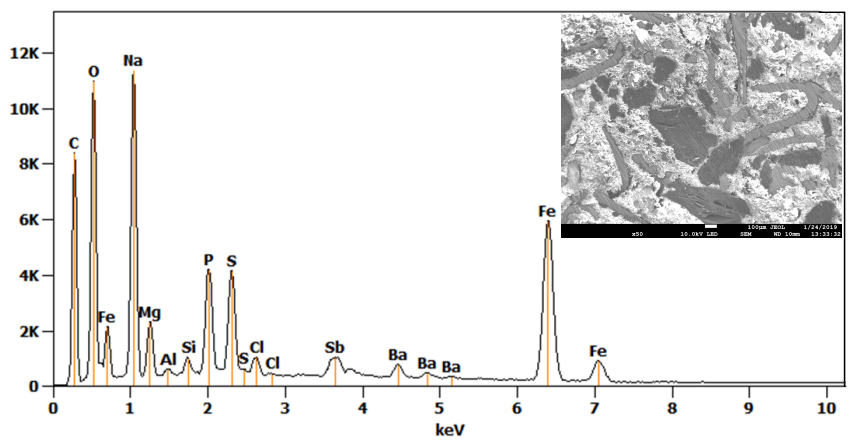

Fig. 3 Elemental spectra of the pad lining compositions.

An EDS analysis on an unworn surface of the pad given in Figure 3 confirms a high proportion of iron (Fe) and carbon (C) as well as oxygen (O). Barium (Ba), antimony $(\mathrm{Sb})$, magnesium $(\mathrm{Mg})$ sulphur $(\mathrm{S})$ are also present in smaller quantities. Other elements, in significant quantities such as sodium (Na) and phosporus $(\mathrm{P})$, 
silicon ( $\mathrm{Si})$ are also detected.

Contrary to the circular pin adopted in the studies of (Wahlström et al., 2010c), (Abbasi et al., 2012a) and (Alemani et al., 2018), the shape of the actual pieces of lining is chosen close to the initial UIC shape of the pad (Figure $4-\mathrm{b}$ )). This allows to respect a residence time of the particle in the real contact and to keep the contact area ratio. The thickness of the pad is the same than the original part. The disc has been cut from the friction track of a full-size disc, as shown in the Figure 4 - a). It corresponds to a half ventilated disc whose blades have been removed to lighten the structure, since the dissipated flow is assumed to be symmetrical on the full-size disc.
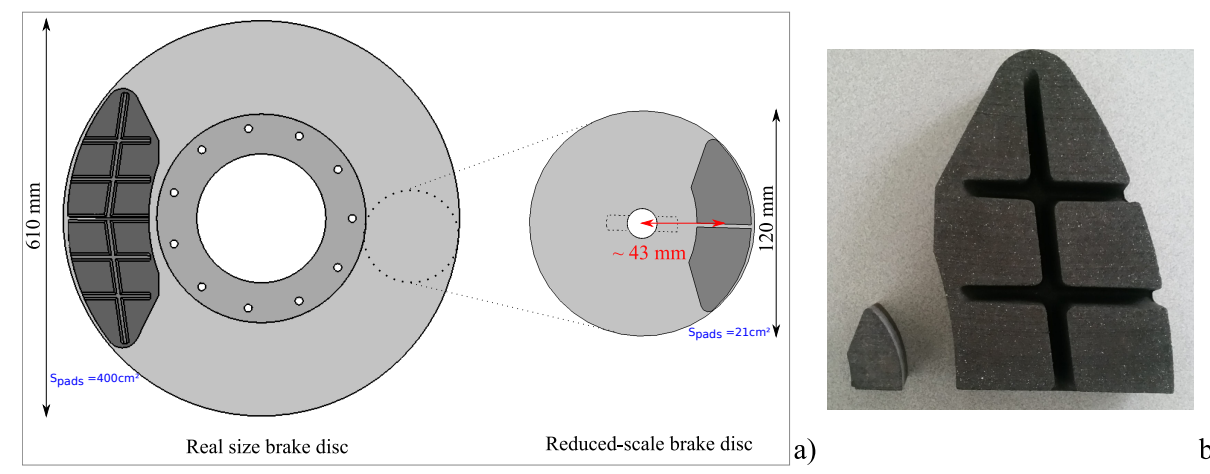

Fig. 4 Representation of the geometry of a) disc and b) pad lining compared to the real scale elements.

The dimensions of each part are chosen to respect the similarity of the heat flow dissipation with the real scale parts as developed by(Roussette et al., 2003). At reduced scale, the sliding velocity is conserved and corresponds to the velocity at the middle of the friction track $(\approx 43 \mathrm{~mm}$ as shown in Figure $4-\mathrm{a}))$. The surface 
of the pads has been reduced from $400 \mathrm{~cm}^{2}$ to $21 \mathrm{~cm}^{2}$. The tests are performed at the same mean contact pressure compared to a full-scale braking device.

The 120-mm-diameter discs and the reduced-pads are cut from the materials using a water jet cutting machine. Before testing, the disc specimens are cleaned using ketone and the pads are cleaned with compressed air. After each assembly of the pads on their support, a running-in procedure is carried out to ensure the flatness of the contact, with approximatively 10 running-in brakes.

\subsection{Preliminary investigation}

The first stage of this study is to evaluate the emissions generated during a typical trip of a Paris interurban rolling stock, by simulating a part of its trip on the HST. Before the test, measurements of the background level are performed to compare with the particle number during friction. These levels are very low, at least 100 times lower for each equivalent diameter. The sliding speed, the contact pressure on the pads and the temperature on the disc rubbing track are plotted in Figure 5 (c) for the typical trip. This presents different initial speeds and braking efforts over more or less short braking duration, which greatly complicates the understanding of particle generation and the influence of braking parameters. In Figure 5 - (a) \& (b) , the particle size and concentration distributions measured over trip duration by the on-line measurement system are represented and can be compared to the applied force values and the surface temperature of the disc on Figure 5 - (c).

A phenomenon can be observed on three of the braking events (braking events 4, 5 and 7 on Figure $5-$ b)): a generation of a larger quantity of particles with a diameter of less than $300 \mathrm{~nm}$ occurs. Each time this fraction of sub-300 nm 

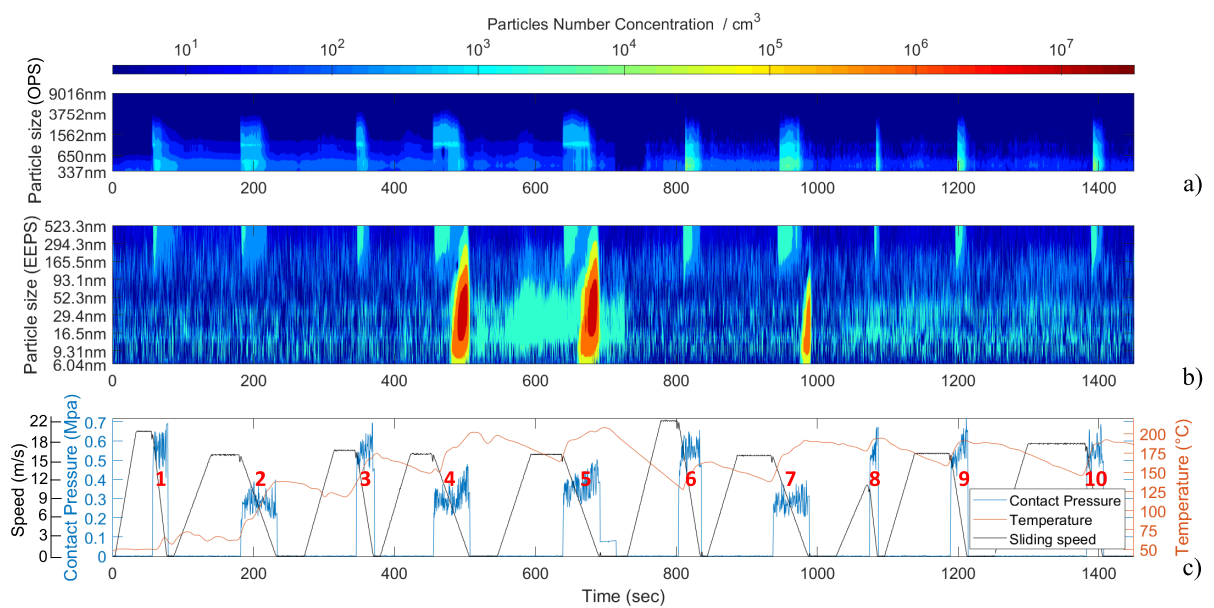

Fig. 5 Size distribution of the airborne wear particles emitted during the first braking events of a typical trip. a) Obtained by OPS, b) obtained by EEPS and c) the associated contact pressure, speed and temperature curves.

particles is emitted, the temperature in the contact exceeds $180^{\circ} \mathrm{C}$. Moreover, The contact force applied seems to be the same for these three braking events: low, around $600 \mathrm{~N}$ (or about $0.3 \mathrm{MPa}$ ) and the braking time is similar (about $50 \mathrm{~s}$ ), which is longer than the other braking events. However, the temperature remains above $180^{\circ} \mathrm{C}$ in subsequent braking operations presenting different braking profile (shorter and more intense braking efforts) and therefore, this phenomenon does not occur (See braking $n^{\circ} 6$ and $n^{\circ} 8$ ). Moreover, at the beginning of the trip, braking with the same profiles does not generate ultra-fine particles (braking $\mathrm{n}^{\circ} 2$ ).

From these findings, several assumptions can be drawn:

- For the same given braking profile, the generation of a high quantity of ultrafine particles is dependent on the temperature in the contact. 
- For the same contact temperature considered, sub-300 nm particles are generated only under certain braking conditions.

In the second assumption, it can be mentionned that the dissipated energy is not the same between the different braking operations performed for a contact temperature higher than $180^{\circ} \mathrm{C}$. Indeed, between the braking events 7 to 9 , the braking effort, braking duration and sliding velocity are not the same. According to the Equation (1) (Meresse et al., 2013), the energy dissipation is dependent on four typical brake system parameters: the friction coefficient $\mu$, the normal force $F_{N}$, the sliding velocity $V$ and the braking duration $t$.

$$
E=P \times t=\mu F_{N} V \times t
$$

Consequently, these braking operations $\left(n^{\circ} 7\right.$ to $\left.n^{\circ} 9\right)$ do not dissipate the same amount of energy. Thus we consider necessary to control the operating conditions to study the influence of these parameters. For this purpose, we choose to carry out the tests for an energy dissipation considered constant, while varying either the application force (or contact pressure), the rotational speed of the disc and/or the contact, and the duration of the braking application.

In the following part of the study, the result for the on-line experiments are obtained at a rotational speed of $2200 \mathrm{rpm}$ (i.e. a train speed of $50 \mathrm{~km} / \mathrm{h}$ ). Three application pressures were considered $(0.25,0.40$ and $0.65 \mathrm{MPa})$, corresponding to the application pressure values relative to the typical trip taken by the train ("normal" service brake, "maximum" service brake and emergency brake respectively). The braking duration are respectively set at 20, 12 and 8 seconds assuming that the friction coefficient variation are low. A mean value of 0.30 for all braking events 
was measured with this pair of friction materials. The temperature evolves from $50^{\circ} \mathrm{C}$ (which is the minimum temperature detected by the pyrometer) to $300^{\circ} \mathrm{C}$, depending on the operating conditions considered.

As the braking conditions does not change from one brake to another during the test, the temperature increase remained constant during each braking event, with a surface heating of less than $30^{\circ} \mathrm{C}$ to keep a comparable dissipative energy. The Table 2 lists the estimated target test values.

Table 2 Considered values for the braking conditions.

\begin{tabular}{|c|c|c|c|c|c|c|}
\hline Test & $\begin{array}{c}\text { Rotational speed } \\
\mathrm{N}^{\circ}\end{array}$ & $\begin{array}{c}\text { Pressure } \\
(\mathrm{rpm})\end{array}$ & $\begin{array}{c}\text { Normal load } \\
(\mathrm{MPa})\end{array}$ & $(\mathrm{N})$ & $\mathrm{t}$ & $\mathrm{E}$ \\
\hline 1 & 0.25 & $\approx 520$ & 0.3 & 20 & \\
2 & 2200 & 0.40 & $\approx 850$ & 0.3 & 12 & 43 \\
3 & & 0.65 & $\approx 1360$ & 0.3 & 8 & \\
\hline
\end{tabular}

\section{Results and Discussions}

\subsection{On-line experiments}

The first approach consist of obtaining the particle distribution over time by fixing the rotational speed, the braking duration and the contact pressure. For each braking event, the temperature increase is lower than $30^{\circ} \mathrm{C}$ which can be considered more or less constant for one event. By repeating the braking operation, the temperature effect is studied with the heat accumulation in the materials. The friction coefficient $\mu$ is obtained from the load sensor. It is from the same order of 
magnitude in each case (see Figure 6). However, it seems that it decreases with the increase of the contact pressure.

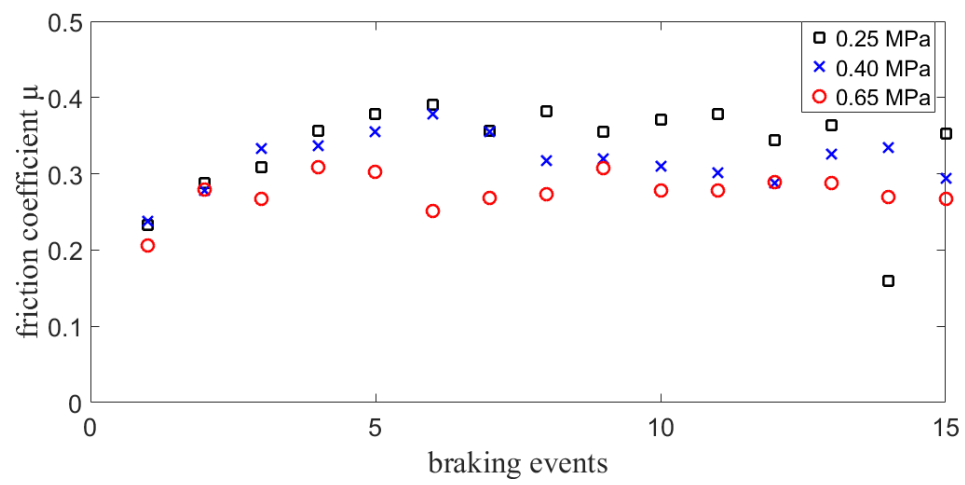

Fig. 6 Representation of the different friction coefficient $\mu$ for each braking events of the three test sequences.

For each of the three contact pressures studied, Figure 7 shows the particle size spectrum obtained and the associated operating conditions (surface temperature, train speed and contact pressure between disc and pads).

According to these number size distributions (Figure 7), most of the detected particles have a diameter of less than $3 \mu \mathrm{m}$. As with the typical train trip simulation (Figure 5), for some braking events, ultra-fine particles (with diameter less than $100 \mathrm{~nm}$ ) are produced in large quantities, in all three cases. The contact pressure as well as the braking duration are different in these three cases, but the trend remains the same.

- In the first case (Figure 7 - a)), from the $6^{\text {th }}$ braking event (black arrow), the nano-particles fraction appears in a greater concentration. The temperature in the contact is then around $230^{\circ} \mathrm{C}$ and does not drop below, until the end of the sequence. 


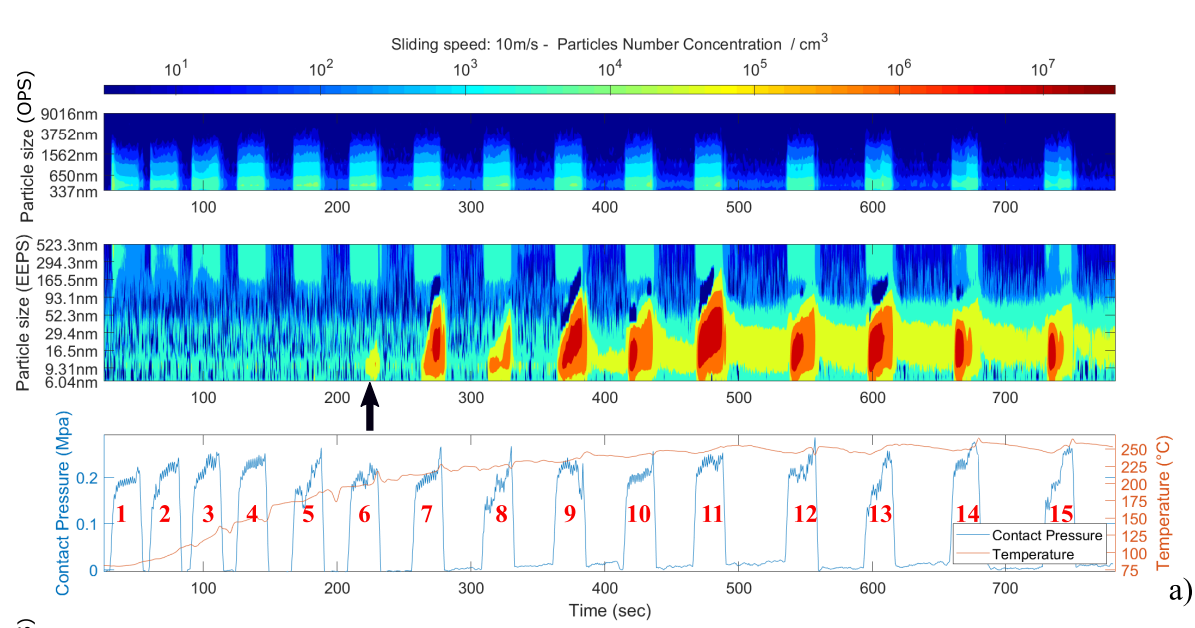

ธิ
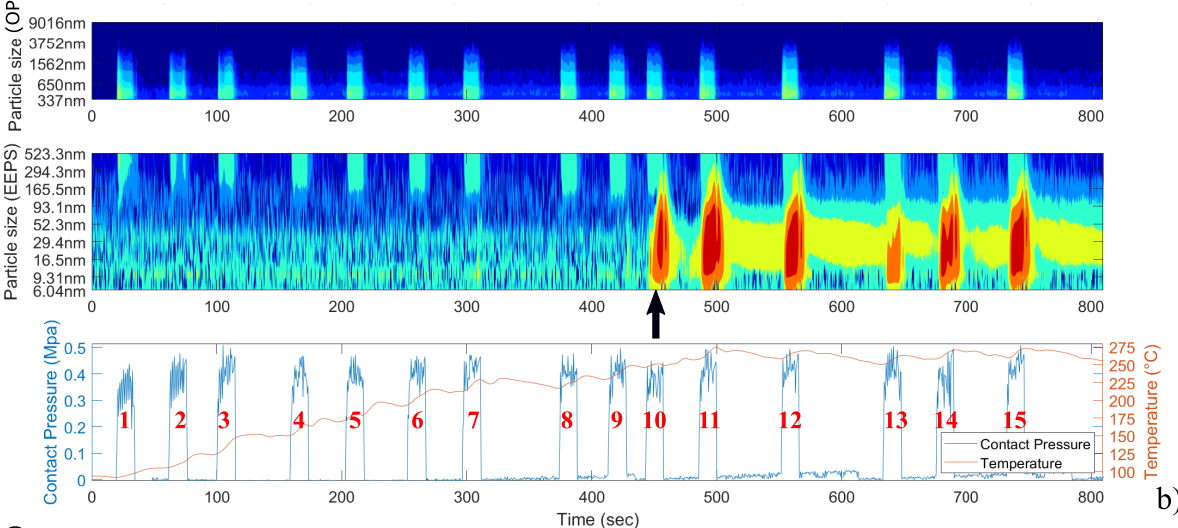

जิ Time (sec)

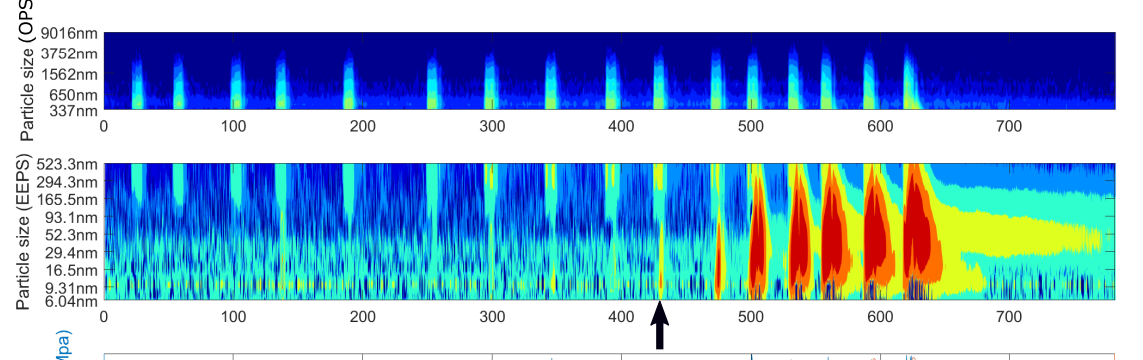

Fig. 7 Spectrum of generated particulate emissions, a) to $0.25 \mathrm{MPa}, \mathrm{b}) 0.40 \mathrm{MPa}$ and c) 0.65 $\mathrm{MPa}$, for a rotational speed of $2200 \mathrm{rpm}(50 \mathrm{~km} / \mathrm{h})$. 
- Similarly, in the second case (Figure 7 - b)), the fraction of nano-particles appears from the $10^{\text {th }}$ braking operation, at a temperature of about $260^{\circ} \mathrm{C}$.

- In the last case (Figure 7 - c)), the same phenomenon appears clearly at the $10^{\text {th }}$ braking event, when the temperature exceeds $275^{\circ} \mathrm{C}$.

From this Figure 7, we can see a phenomenon of accumulation of particles in the ultra-fine fraction between each braking. This accumulation can affect the reading of data and the actual concentrations emitted during braking. These results are in line with the conclusions made by (Garg et al., 2000), (Kukutschová et al., 2011) and (Alemani et al., 2015), showing that high concentrations of nano-particles fraction are emitted when the temperature is approximately $300^{\circ} \mathrm{C}$. However, we note that the phenomenon appears at different temperature values when increasing contact pressure. In order to confirm this trend and to better assess particle size, the size distributions in number, at three different temperatures and for the three different contact pressures considered, are given in Figure 8. Each graph represents the number distribution of particles by size for 9 isolated braking operations taken from the spectra in Figure 7 at comparable contact pressures and temperatures.

Figure 8 clearly shows that beyond a temperature that we will call "Transitional temperature" $\left(T_{t}\right)$, ultra-fine particles are emitted in greater proportions. This transitional temperature is higher when the contact pressure is higher and thus, braking duration shorter. Below $T_{t}$, the observed particle number size distributions denotes three size fractions for each case study: two ultra-fine particle fractions around $10 \mathrm{~nm}$ and $30 \mathrm{~nm}$ and a fine particle fraction around $300-400$ nm. Above $T_{t}$, a single fraction of ultra-fine particles appears $(20-40 \mathrm{~nm})$ and its concentration is increasing by several orders of magnitude in each case (from 

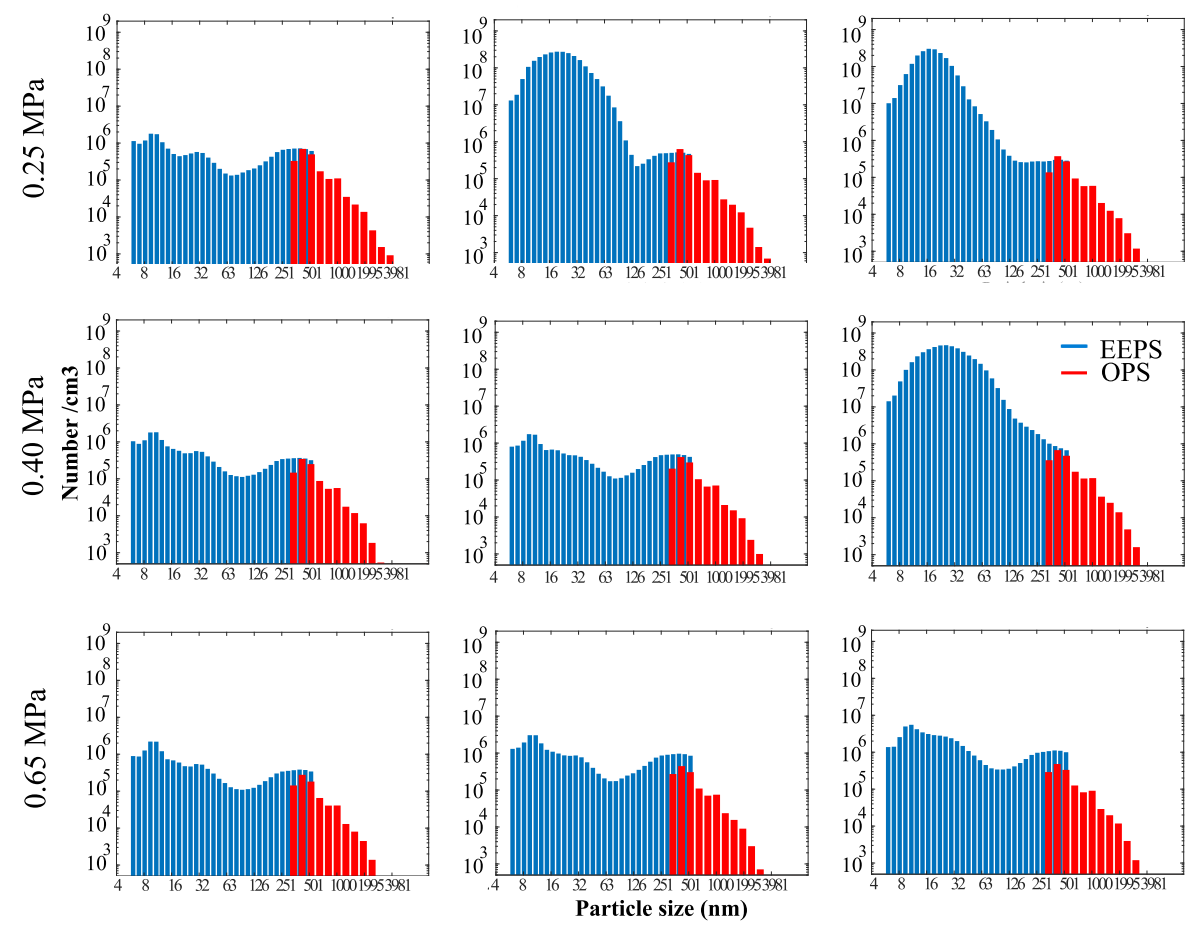

$180^{\circ} \mathrm{C}$ $230{ }^{\circ} \mathrm{C}$

$250^{\circ} \mathrm{C}$

Fig. 8 Comparison of the number size distribution of the airborne wear particles for the three contact pressure at $180^{\circ} \mathrm{C}, 230^{\circ} \mathrm{C}$ and $250^{\circ} \mathrm{C}$.

about $10^{7}$ particles $/ \mathrm{cm}^{3}$ up to $5 \times 10^{8}$ particles $\left./ \mathrm{cm}^{3}\right)$. Comparatively, the fraction of fine particles (300-400 nm) is only slightly affected by temperature variation or pressure intensification.

In several studies (Kukutschová et al., 2011; Mosleh et al., 2004; Wahlström et al., 2010d; Namgung et al., 2016), the presence of mode (or peak) in the size distributions around $300 \mathrm{~nm}$, can be observed for different materials and braking conditions (contact pressure or sliding speed). However, the main notable differences are the intensity of these peaks, which indicated the evolution and the influ- 
ence of some of these parameters on the quantity and size of the particles emitted. In their investigations on truck brake materials, (Mosleh et al., 2004) observed that the sizes associated to the peaks were independent to braking conditions and they noted that when the contact pressure increased, the amount of larger particles increased. (Wahlström et al., 2010d), who conducted test on three different scales (field tests, disc brake assembly test stand and pin-on-disc tests), also found a peak at 300-400 nm, but questioned the latter conclusions (Mosleh et al., 2004), considering that the method used took into account all emitted particles and not only airborne particles. According to them, the entire size range should have been impacted by the increase in contact pressure, not just the larger ones. They also remarked that the distribution may not be sensitive to the applied load or braking conditions, which was also assumed by (Alemani et al., 2018) who explored the influence of sliding velocity and contact pressure on low-steel materials. (Namgung et al., 2016) observed that increasing braking force without changing the speed led to the increase in concentration of the $10 \mathrm{~nm}$ peak. It has not been specified whether the braking time and therefore the dissipated energy had been kept constant, which can then implied that the increase in dissipated energy increases the amount of particles emitted. In the present study, the contact pressure does not seem to directly influence the size distributions of the emitted particles, but it seems to affect the transitional temperature at which the ultra-fine fractions will appear, as observed by (Alemani et al., 2015).

For the other peaks in the number distributions (Figure 8), other studies have observed similar peaks. (Garg et al., 2000) conducted brake dynamometer tests on seven different brake materials and found the highest number of emitted particles 
had diameters smaller than $30 \mathrm{~nm}$. (Namgung et al., 2016) conducted tests on metro train organic brake pads using a brake dynamometer and the same on-line measurement devices used in the present study. They observed the same peaks at $10 \mathrm{~nm}, 30 \mathrm{~nm}$ and also 178-275 nm for different braking conditions. From all those studies, the conclusion was set that the ultra-fine particle fraction $(<100 \mathrm{~nm})$ was attributable to temperature rise and the burning of the organic compounds of the friction materials (Kukutschová et al., 2011).

Another point, raised by (Abbasi and Sellgren, 2013), is that particle size distributions, in terms of number or volume, are time and temperature dependent, and the authors insisted in the fact that techniques are needed to sample airborne wear particles in real time. All recent studies have examined particles as collected on filters, studying them all together at the same time, neglecting when each particle was collected. The online measurement approach proposed here makes it possible to identify when the fine and ultra-fine particles are emitted during braking event. (Namgung et al., 2016) also observed a change in the number distribution of the particles depending on the braking duration.

\subsection{Focus on a single braking event}

Figure 9 shows the instantaneous measurement of particles emitted during three braking operations previously shown in Figure 7 - b) at different contact temperature in the case that a pressure of $0.25 \mathrm{MPa}$ is applied. The grey areas on 

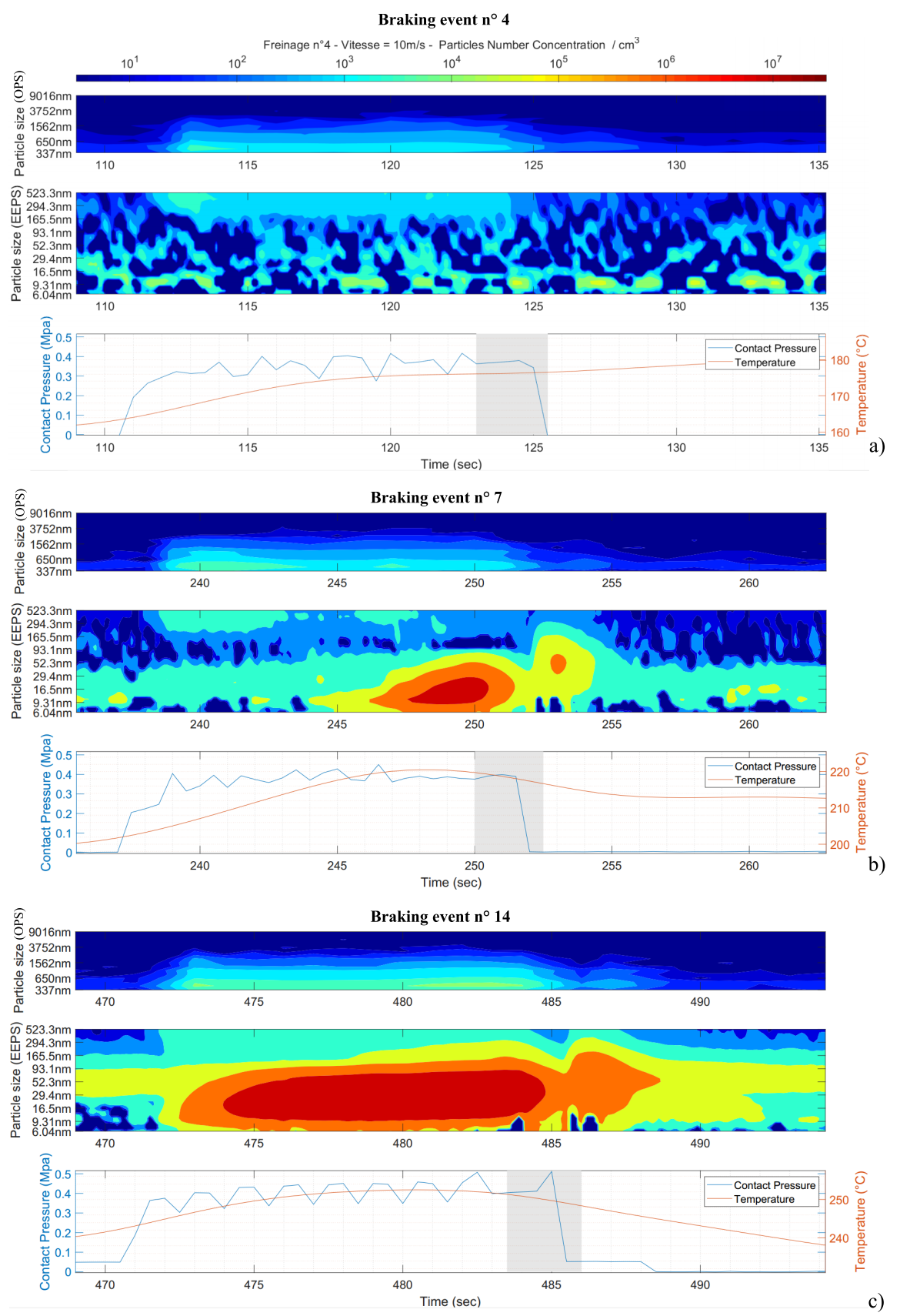

Fig. 9 Spectrum of generated particulate emissions at $0.25 \mathrm{MPa}$ for braking events, a) 4, b) 7 and c) 13 . 
the graphs represent the duration without disc rotation. These images show the dependency on time and temperature suggested by (Alemani et al., 2018).

- In the first braking event presented (Figure 9 - a)), particles with diameters between $150 \mathrm{~nm}$ and $4 \mu \mathrm{m}$ are emitted in relatively small quantities (from an order of $10^{4}$ particle $\left./ \mathrm{cm}^{3}\right)$. The disc surface temperature does not exceed $175^{\circ} \mathrm{C}$ during this braking event. The peaks in concentration within the EEPS spectrum is attributable to the presence of pollutants in the ambient air. As EEPS measures electric mobility, interactions can occur between the device and pollutants in the ambient air, generating artifacts.

- During the second braking event (Figure 9 - b)), there are 3 stages in the PM emission. At the beginning of braking event, the largest particles are emitted (between $150 \mathrm{~nm}$ and $3.5 \mu \mathrm{m}$ ) then a few moments later, particles of sizes less than $100 \mathrm{~nm}$ are emitted until the disc is no longer rotating (gray area in the Figure 9). Then the emission seems to restart while the disc is still not rotating (PM of 50 to $300 \mathrm{~nm}$ in size). The maximum temperature in the contact reaches $220^{\circ} \mathrm{C}$ and corresponds to the moment when the quantity of ultra-fine particles is maximum (about $10^{7}$ particles $/ \mathrm{cm}^{3}$ ).

- Finally, in the last braking operation (Figure 9 - c)), there are only two emissions appearing. Fine and ultra-fine particles are emitted simultaneously and a second emission also occurs at the end of the braking event.

This second emission in the ultra-fine fraction is attributed here to the release of particles caused by the disconnection of the brake linings from the disc surface. This contact disconnection will cause the removal of particles in the contact while ambient air is introduced between the two friction parts, and therefore, the parti- 
cles become airborne. This phenomenon associated to a suction process, has not been observed in other studies yet, however, (Namgung et al., 2016) observed the delay between fine and ultra-fine fractions emissions.

\subsection{Off-line measurements}

In the second approach, collection experiments are undertaken to further characterize the generated particles and to compare different methods of sizing analysis. In these experiments, the analyses are not focused on ultra-fines particles because the devices for size measurement and SEM are not adapted. However these results give information on the nature and the shape of coarses particles. The samples are obtained through a succession of 50 braking operations assumed to be identical. The rotational speed and application pressure were set and the temperature was maintained almost constant for each brake application. The operation conditions considered are the same as the ones for on-line experiments (Table 2). The temperature is set at $100^{\circ} \mathrm{C}, 180^{\circ} \mathrm{C}$ and $260^{\circ} \mathrm{C}$ for the three different experiments, leading to 9 different test sequences of 50 braking events. In that purpose, the brakes are manually triggered when the disc surface temperature reaches the target values above. The collected particles are stored and then analyzed using optical analysis instruments (MasterSizer3000, SEM-EDS) to determine their size distribution, morphology and elemental composition.

Figure 10 represents the particle size distributions according to their densities in number and volume for the 9 tests performed. The particle number distribution obtained from the collection tests shows that most of the particles have a sub- 

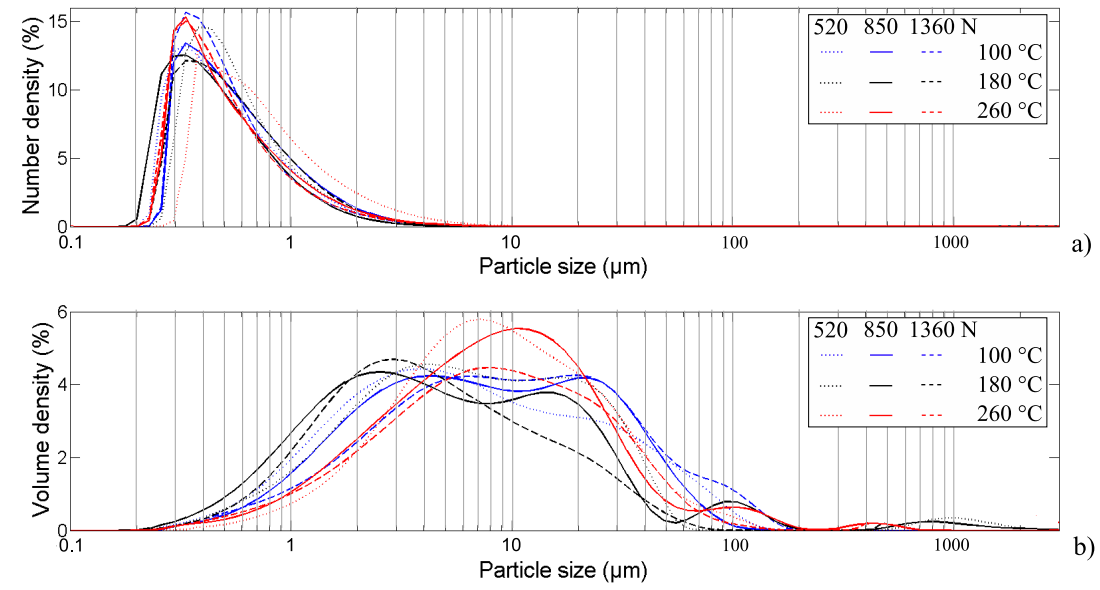

Fig. 10 Size distributions obtained from the different tests conducted at $2200 \mathrm{rpm}$. a) Number density size distribution and b) Volume density size distribution.

micron size (Figure $10-a)$ ), which is consistent with the results obtained during the on-line tests.

Most of the detected particles have a size between $200 \mathrm{~nm}$ and $7 \mu \mathrm{m}$, with a high proportion around the 200-600 nm fraction for all tests performed, corresponding to the fraction of fine particles in the on-line tests. In comparison, the volume distribution (Figure 10 - b)) shows a much wider particle distribution, ranging from $200 \mathrm{~nm}$ to up to $1 \mathrm{~mm}$. There are several modes observed on the different test curves that may be broadly related to specific particle size ranges: a fraction around 2-5 $\mu \mathrm{m}$, another around 8-15 $\mu \mathrm{m}, 15-30 \mu \mathrm{m}$ and finally, one around $100 \mu \mathrm{m}$. These particles do not appear in the number distribution because although they represent a large volume, their number is low. It can also be seen that the large number of particles (200-400 $\mathrm{nm}$ ) represent a very small volume of the analyzed particles. Particles whose volume represents the major part of the 
emitted particle's volume are between 1 and $30 \mu \mathrm{m}$.

The influence of temperature and pressure parameters does not seem relevant in this type of analysis, as for the different contact pressures and surface temperatures tested, the curves do not show any significant difference. In Figure 11, the different friction coefficients measured during each test sequence are represented.

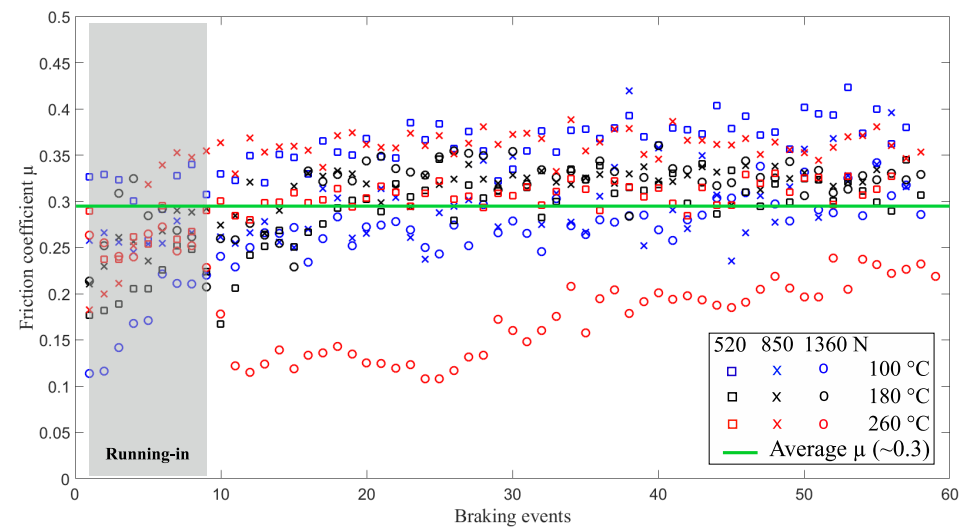

Fig. 11 Representation of the different friction coefficient $\mu$ for each braking events of each test sequences.

For all braking conditions considered, the mean value is close to the assumed value for the dissipative energy calculation (Table 2). Severe conditions (0.65 MPa; $260^{\circ} \mathrm{C}$ ) appear associated to low friction coefficient in the corresponding test sequence. However, it can be observed that for the contact temperatures and pressures considered, the height associated to the peak (between 200 and $600 \mathrm{~nm}$ ) remains approximately unchanged. The number density therefore remains unchanged under all tested conditions. However, this does not mean that the quantity of PM remains constant. Furthermore, it should be noted that the detection limits 
of the device do not allow the measurement of particles smaller than $100 \mathrm{~nm}$. Thus, it could not be confirmed that temperature rise generates more ultra-fine and fine particles or that the increase in contact pressure changes the size distribution. However, considering the previous observations made on the fine particles fraction independence to temperature and contact pressure rises, the results presented in Figure 10 are consistent.

To evaluate the quantity, the pads were weighted before and after the cycle of braking events. The mass losses of the 9 conditions tested are given in Table 3. This confirm differences in pads wear for a given dissipated energy. The mass loss is always higher for the tests performed at $260^{\circ} \mathrm{C}$. It is more difficult to conclude on other influences. The mass losses for the test at $100^{\circ} \mathrm{C}$ and at $180^{\circ} \mathrm{C}$ are quite similar. Furthermore the influence of the temperature has also been noticed on the opacity of the wet solution containing the recovered particles. The wet solutions for the tests at $260^{\circ} \mathrm{C}$ are darker than the others conditions.

\begin{tabular}{|l|c|c|c|c|c|c|c|c|c|}
\hline Contact Pressure & \multicolumn{3}{|c|}{$0.25 \mathrm{MPa}$} & \multicolumn{3}{c|}{$0.40 \mathrm{MPa}$} & \multicolumn{3}{c|}{$0.65 \mathrm{MPa}$} \\
\hline Brake event duration & \multicolumn{3}{|c|}{$20 \mathrm{~s}$} & \multicolumn{3}{c|}{$12 \mathrm{~s}$} & \multicolumn{3}{c|}{$8 \mathrm{~s}$} \\
\hline Temperature $\left({ }^{\circ} \mathrm{C}\right)$ & 100 & 180 & 260 & 100 & 180 & 260 & 100 & 180 & 260 \\
\hline Mass Loss $(\mathrm{g})$ & 0.57 & 0.48 & 0.87 & 0.13 & 0.42 & 0.94 & 0.6 & 0.54 & 1.42 \\
\hline
\end{tabular}

Table 3 Mass loss of the braking pads after 50 braking events 
3.4 Particle morphology and elemental composition

The chemical composition of brake wear particles should be taken into account when trying to characterize them and assess their possible adverse effects on human health (Grigoratos and Martini, 2015). Their composition have as well an influence on their propagation in the surroundings. According to the Stokes Number given by the equation (2), the behaviour of a particle transported by a fluid is given according its size (mean diameter $\mathrm{d}_{p}$ ), their density $\rho_{p}$ (so their composition), the velocity of the fluid $\mathrm{U}_{f}$ and the dynamic viscosity of the fluid $\mu_{f}$.

$$
S t k=\frac{\rho_{p} * d_{p} * U_{f}}{18 \mu_{f}}
$$

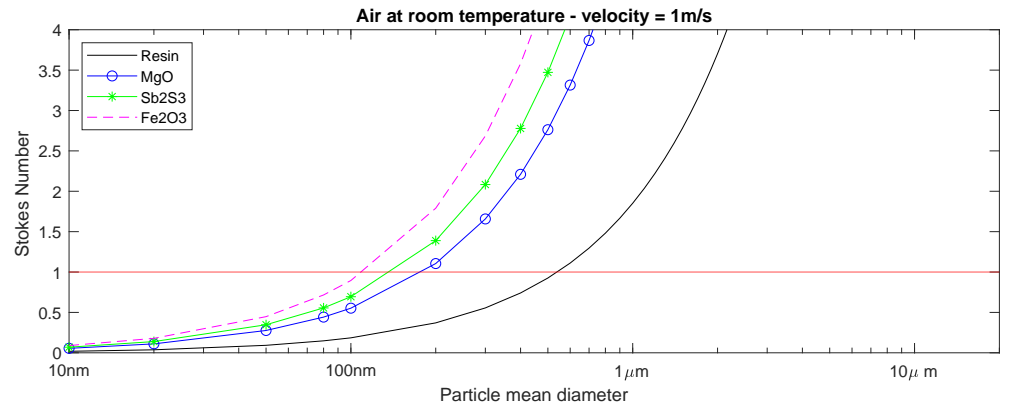

Fig. 12 Stokes Number according to mean particle diameter and composition

The Stokes number is a dimensionless number used to evaluate the relative importance of inertial force with the viscous dissipation force in the fluid. In viscous regime $($ Stk $<<1)$, the particles follow the fluid streamlines. For a large number $($ Stk $>>1)$, the particles are driven by their inertia and their trajectory becomes slightly influenced by the fluid flow. Then the transportation of the resin particles in the air will differ with the heavier particles like Iron oxides or Barium Sulfate. This is illustrated on Figure 12. The Stokes Number is plotted according to the 
mean diameter of a particle for the major compounds of the brake pads and for an unitary velocity speed of the air. A speed of $1 \mathrm{~m} / \mathrm{s}$ is representative of standing air medium in underground station.

According to density of the main compounds in the brake pads (see Table 1), it can be observed that at low velocity resin particle will follow the fluid for diameter under 500nm. However, the inertia forces have a non-negligeable effect on the other components until 100-200nm.

SEM images showed that the particles have various shapes and sizes. Small spherical particles, flakes-like particles of several microns in size (red arrows) and agglomerates (white arrows) can be observed (Figure 13).

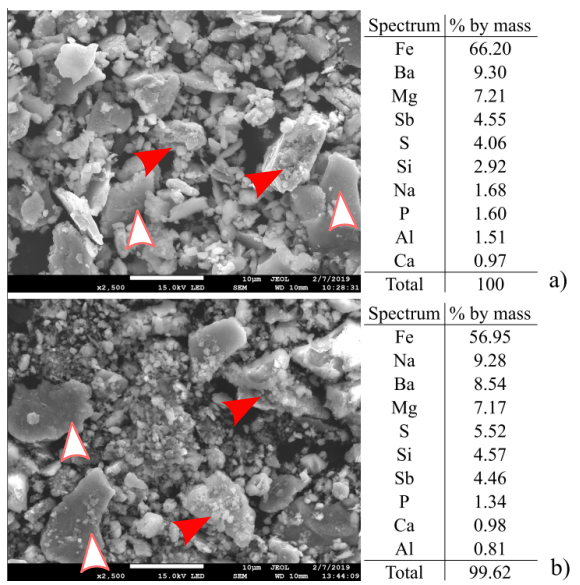

Fig. 13 SEM images and elemental spectrum of particles collected from a) the ${ }^{\prime} 260^{\circ} \mathrm{C}$, $0.40 \mathrm{MPa}$ " sample and b) the " $180^{\circ} \mathrm{C}, 0.40 \mathrm{MPa} "$ sample. Red arrows indicate aggregates and white arrows indicate flakes.

Flakes-like particles are larger and flatter with sharp edges. Most of the largest particles are flakes. This type of particles is also reported by (Kukutschová et al., 
2011), (Loxham et al., 2013) and (Nosko et al., 2017). According to (Mosleh et al., 2004), those flaky particles are the result of compaction of wear debris during braking. The formation of primary and secondary plateaus of contact have been highlighted by (Eriksson et al., 2002). The coarses particles emitted may come from the deterioration of these plateaus. The SEM-EDS images show a significant number of larger particles (with diameters of several microns) which do not clearly appear in the size distributions in on-line distribution measurements (Figure 8). This may be due to their volume which is 100 times larger than ultra-fine particles and makes them more visible on SEM images even if these flakes-like particles are present in a smaller proportion in number. Another explication could be the orientation of the particle as it passes through the analysis area. These flakes-like particles are often half as thick as their height or width.

It is also interesting to note that an agglomeration phenomenon may have occurred within the particles between their generation and analysis, which may distort the data obtained by analysis. This is especially verified by the SEM images, presented in Figure 13, clearly showing aggregates of fine particles.

Indeed, (Namgung et al., 2016), (Kukutschová et al., 2011) and (Abbasi and Sellgren, 2013; Abbasi et al., 2012b) also observed aggregates of nano-sized particles of diameter less than $40 \mathrm{~nm}$ with spherical shapes. The analyzed particles were not collected and stored as we did in this study. Thus, we can also assume that some of the observed aggregates might be formed during braking events. (Garg et al., 2000), (Sanders et al., 2003) and (Loxham et al., 2013) presumed that the aggregation is attributable to speed and temperature of brake discs and pads. (Namgung et al., 2016) considered that the ultra-fine particles with diameters lower than $40 \mathrm{~nm}$ were generated by evaporation/condensation process with aggregation of 
primary nano-particles than by abrasive wear. As noted by (Kukutschová et al., 2011), aggregates and ultra-fine particles tend to strongly adhere to coarser particles, which can be observed here, on SEM images (Figures 13 and 14).

The elemental composition of these particles emitted during the tests has been conducted using SEM-EDS and is primarily Fe, Ba, Mg, S, Si and Sb with small proportions of $\mathrm{P}, \mathrm{Ca}, \mathrm{Al}$ and $\mathrm{Na}$ (Figure 13). Most of the identified elements correspond to the elements present in the pad lining before testing (Figure 3). However, this EDS analysis is semi-quantitative: the proportions of carbonaceous compounds and oxygen are not given here, although they are present in large quantities. The reason is the EDS analysis is done on carbon adhesive, which distorts the measurement of carbonaceous compounds, giving much higher proportions than in reality. Therefore, it is important to note that the PM has a significant amount of carbon that could not have been clearly identified. The other elements present in the composition of the wear particles, such as Ca, may be either from the pollution of the sample during collection and/or storage, from compounds present in small quantities in the linings or from the surface of the disc. The difference between the two spectra proposed, in Figure 13 - a) and - b), is that the amount of $\mathrm{Na}$ has been multiplied by 5 , while S increases by $35 \%$ and $\mathrm{Si} 56 \%$ with increasing contact temperature. The amount of Fe decreases by $14 \%$ and Ba by about $9 \%$. The amount of $\mathrm{Al}$ is halved, but was already very low.

An EDS analysis on flaky particles and aggregates shows that both have a fairly similar composition (Figure 14). These particles are mainly composed of Fe and Ba. Composition variations are mainly due to lower proportions of elements, such 
as $\mathrm{Mg}, \mathrm{Sb}$ and $\mathrm{S}$. From one particle to another with the same aspect, we observe that the proportions of each of the above-mentioned elements are generally from the same order of magnitude.

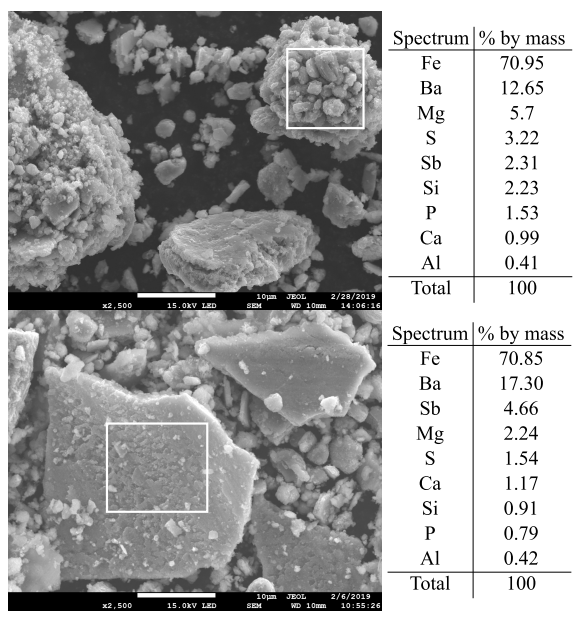

Fig. 14 SEM images and elemental spectrum of a) some agglomerates and b) flakes-like particles.

While SEM and EDS provided valuable morphological and compositional information about elements in the emitted PM, they does not give any information about the specific compounds in the debris. Increase in contact temperature during braking events can alter the chemistry of the contact surfaces, the transfer film and the ejected particles. Therefore, the chemistry of brake wear particles may be considerably different that of the starting materials even if the same elements are in presence. These observed differences in element's proportions may be isolated and random phenomena, as it may also be true results. The variety of results in the literature and the dependence on the initial composition of the materials in contact do not allow us today to clearly state the variation in the composition of 
the particles emitted as a function of braking conditions and the temperature in contact. Therefore, these observations remain limited and further study would be necessary to verify the real influence of braking parameters on the composition of the emitted particles.

\section{Conclusion and perspectives}

The study presented in this contribution, focused on the characterization of PM emissions during friction between the cast iron disc and the organic linings of a rail braking system. The tests are conducted on a high speed tribometer (HST) to reproduce braking on a reduced scale system. The study is carried out at a constant rotational speed (corresponding to $50 \mathrm{~km} / \mathrm{h}$ ) with three different braking forces on more or less long braking duration in order to have the same dissipated energy on each test. Two approaches are considered to characterize PM emissions: an instantaneous measurement approach and a post-test characterization approach. The real-time size distribution, morphology and element composition of the PM are presented. Following these tests, several conclusions can be drawn:

- For the same given braking profile, the generation of a high quantity of ultrafine particles $(<100 \mathrm{~nm})$ is highly dependent on the temperature in the contact, as found in the literature (Kukutschová et al., 2011; Garg et al., 2000; Alemani et al., 2018). It is observed that the amount of ultra-fine particles is drastically increased when the temperature reaches a transitional value, higher than $180^{\circ} \mathrm{C}$. This activation temperature is found to be dependent of the braking conditions while keeping the same dissipative energy. To the authors knowledge, this phenomena has not been discussed in previous studies. 
- For the same contact temperature considered, ultra-fine particles are generated only under certain braking conditions. In the typical trip, even if the contact temperature is similar during different braking operations, the difference in dissipative energy generates different emissions profiles.

- The fine particle fraction (with diameter around $500 \mathrm{~nm}$ ) seems not to be affected by temperature changes and/or contact pressure variations. In all presented results, the size distributions is similar although braking conditions changed, in on-line and off-line analyzes.

- The emission of particles during braking is done in steps according to the temperature in the contact. The coarser particles are first emitted, then the ultra-fine particles are emitted when the temperature increases. This is especially observed when the temperature in the contact is close to the transition temperature of $180^{\circ} \mathrm{C}$.

- A second emission of particles occurs when the contact between the disc and the lining is broken, at the end of the braking process. It can be associated with a suction phenomenon that causes air to move between the two parts and removes the particles from the surface of the parts. This can represent a real health issue when the train is leaving, particularly in confined environment like underground station.

- The shape of the particles are various. There are many flakes and agglomerates of ultra-fine particles, which is similar with other studies carried out under different braking conditions and on other materials.

- The elementary composition of the particles is close to the initial composition of the linings. However, this does not mean that the compounds have not changed under the different stresses imposed and temperature rises. 
The results presented in this study will be used to provide a numerical model to predict the evolution of these particles and their behavior in the air flow generated by train traffic, in particular to address the risks of exposure of commuters in stations and on the platforms.

\section{Acknowledgment}

This work was carried out within the framework of Research on Ground Transports and Mobility by the French National Scientific Research Center CNRS, in coordination with the ELSAT2020 project supported and financed by the European Community, the French Ministry of Higher Education and Research, the Hauts-de-France Regional Council. The authors gratefully acknowledge and appreciate the support of all these institutions. It was also supported by ALSTOM SA, which funds a part of the present research work.

\section{References}

Abbasi S, Sellgren U (2013) Technical note: Experiences of studying airborne wear particles from road and rail transport. Aerosol and Air Quality Research 13: 1161-1169, 2013. doi: 10.4209/aaqr.2012.10.0295.

Abbasi S, Jansson A, Olander L et al (2012)A pin-on-disc study of the rate of airborne wear particle emissions from railway braking materials. Wear 284-285: 18-29. doi: 10.1016/j.wear.2012.01.016.

Abbasi S, Olofsson U, Sellgren U (2012) A field test study of airborne wear particles from a running regional train. Proceedings of the Institution of 
Mechanical Engineers Part F : Journal of Rail and Rapid Transit. doi: $10.1177 / 0954409711408774$.

Alemani M, Nosko O, Metinoz I, Olofsson U (2015) A study on emission of airborne wear particles from car brake friction pairs. SAE Int. J. Mater. Manuf. 9:147157. doi: $10.4271 / 2015-01-2665$.

Alemani M, Wahlström J, Olofsson U (2018) On the influence of car brake system parameters on particulate matter emissions. Wear 396-397:67-74. doi: 0.1016/j.wear.2017.11.011.

Clifford S, Mazaheri M, Salimi F et al (2018) Effects of exposure to ambient ultrafine particles on respiratory health systemic inflammation in children. Environ. Int. 114:167-180. doi: 10.1016/j.envint.2018.02.019.

Eriksson M, Bergman F, Jacobson S (2002) On the nature of tribological contact in automotive brakes. Wear 252(1):26 - 36. doi: https://doi.org/10.1016/S00431648(01)00849-3.

Franck U, Odeh S, Wiedensohler A et al (2011) The effect of particle size on cardiovascular disorders - the smaller the worse. Sci. Total Environ. 409(20): 4217-4221. doi: 10.1016/j.scitotenv.2011.05.049.

García E, Sánchez J, Meresse D et al (2014) Complementary tribometers for the analysis of contact phenomena in grinding. Journal of Materials Processing Technology 214(9):1787-1797. doi: 10.1016/j.jmatprotec.2014.03.026.

Garg B, Cadle S, Mulawa P, et al (2000) Brake wear particulate matter emissions. Environ. Sci. Technol. 34:4463-4469. doi: 10.1021/es001108h.

Grantz D, Garner J, Johnson D (2003) Ecological effects of particulate matter. Environ Int. 29(2-3):213-39. doi: 10.1016/S0160-4120(02)00181-2. 
Grigoratos T, Martini G (2015) Brake wear particle emissions: a review. Environ. Sci. Pollut. Res. 22:2491-2504. doi: 10.1007/s11356-014-3696-8.

Hansen J, Sato M, Ruedy R et al (2016) Global warming in the twenty-first century: An alternative scenario. Proceedings of the National Academy of Sciences of the United States of America 97(18):9875-9880. doi: 10.1073/pnas.170278997.

Kukutschová J, Moravec P, Tomáš̌ek V et al (2011) On airborne nano/micro-sized wear particles released from low-metallic automotive brakes. Environ. Pollut. 159:998-1006. doi: 10.1016/j.envpol.2010.11.036.

Loxham M, Cooper M, Gerlofs-Nijland M et al (2013) Physicochemical characterization of airborne particulate matter at a mainline underground railway station. Environ. Sci. Technol. 47(8):3614-3622. doi: 10.1021/es304481m.

Martins V, Moreno T, Minguillón M. C et al (2015) Exposure to airborne particulate matter in the subway system. Sci. Total Environ. 511:711-722. doi: 10.1016/j.scitotenv.2014.12.013.

Meresse D, Watremez M, Siroux M et al (2013) Friction and wear mechanisms of phenolic-based materials on high speed tribometer. J. Tribol. 135(3). doi: $10.1115 / 1.4023803$.

Mosleh M, Blau P. J, Dumitrescu D (2004) Characteristics and morphology of wear particles from laboratory testing of disk brake materials. Wear 256:1128-1134. doi: 10.1016/j.wear.2003.07.007.

Namgung H, Kim J, Woo S et al (2016) Generation of nanoparticles from friction between railway brake disks and pads. Environ. Sci. Technol. 20(7):3453-3461. doi: $10.1021 /$ acs.est.5b06252.

Nosko O, Alemani M, Olofsson U (2015) Temperature effect on emission of airborne wear particles from car brakes. Europe's Braking Conference and Exhibition 
(EuroBrake). doi: 10.13140/RG.2.1.1237.3209.

Nosko O, Borrajo-Pelaez R, Hedström P, Olofsson U (2017) Porosity and shape of airborne wear microparticles generated by sliding contact between a lowmetallic friction material and a cast iron. J. Aerosol Sci. 113:130-140. doi: 10.1016/j.jaerosci.2017.07.015.

Pascal M, De Crouy Chanel P, Wagner P et al (2016) The mortality impacts of fine particles in france. Sci. Total Environ. 571:416-425. doi: 10.1016/j.scitotenv.2016.06.213.

Querol X, Alastuey A, Ruiz C et al (2004) Speciation and origin of $p m_{10}$ and $p m_{2.5}$ in selected european cities. Atmos. Environ. 38:6547-6555. doi: 10.1016/j.atmosenv.2004.08.037.

Roussette O, Desplanques Y, Degallaix G (2003) Representativite thermique d'essais tribologiques a echelle reduite. Comptes Rendus Mecanique 331(5): 343 - 349. doi: https://doi.org/10.1016/S1631-0721(03)00082-2.

Sanders P, Xu P, Dalka T, Maricq M (2003) Airborne brake wear debris: size distributions, composition, and a comparison of dynamometer and vehicle tests. Environ. Sci. Technol. 37:4060-4069. doi: 10.1021/es034145s.

Solaimani P, Saffari A, Sioutas C et al (2017) Exposure to ambient ultrafine particulate matter alters the expression of genes in primary human neurons. NeuroToxicology 58:50-57. doi: 10.1016/j.neuro.2016.11.001.

Thorpe A, Harrison RM (2008) Sources and properties of non-exhaust particulate matter from road traffic: a review. Sci. Total Environ. 400:270-282. doi: 10.1016/j.scitotenv.2008.06.007.

Wahlström J, Olander L, Olofsson U (2010a) Size, shape, and elemental composition of airborne wear particles from disc brake materials. Tribol. Lett. 38:15-24. 
doi: 10.1007/s11249-009-9564-x.

Wahlström J, Olander L, Olofsson U (2010b) A pin-on-disc study focusing on how different load levels affect the concentration and size distribution of airborne wear particles from the disc brake materials. Tribol. Lett. 46:195-204. doi: $10.1007 / \mathrm{s} 11249-012-9944-5$.

Wahlström J, Söderberg A, Olander L et al (2010c) A pin-on-disc simulation of airborne wear particles from disc brakes. Wear 268:763-769. doi: 10.1016/j.wear.2009.11.014.

Wahlström J, Söderberg A, Olander L et al (2010d) Airborne wear particles from passenger car disc brakes: a comparison of measurements from field tests, a disc brake assembly test stand and a pin-on-disc machine. Proc. IMEchE, Part J: J. Engineering Tribology, 224:179-188. doi: 10.1243/13506501JET633.

Wu CF, Li YR, Kuo IC et al (2012) Investigating the association of cardiovascular effects with personal exposure to particle components and sources. Sci. Total Environ. 431:176-182. doi: 10.1016/j.scitotenv.2012.05.015. 